Article

\title{
Chemical Profiling and Discrimination of Essential Oils from Six Ferula Species Using GC Analyses Coupled with Chemometrics and Evaluation of Their Antioxidant and Enzyme Inhibitory Potential
}

\author{
Fadia S. Youssef ${ }^{1}$ (D), Munira A. Mamatkhanova ${ }^{2}$, Nilufar Z. Mamadalieva ${ }^{2,3}$, \\ Gokhan Zengin ${ }^{4}\left(\mathbb{D}\right.$, Salima F. Aripova ${ }^{2}$, Elham Alshammari ${ }^{5}$ iD and Mohamed L. Ashour ${ }^{1, *(D)}$ \\ 1 Department of Pharmacognosy, Faculty of Pharmacy, Ain Shams University, Cairo 11566, Egypt; \\ fadiayoussef@pharma.asu.edu.eg \\ 2 Institute of the Chemistry of Plant Substances, Academy of Sciences of RUz, Mirzo Ulugbek str. 77, \\ Tashkent 100170, Uzbekistan; munir_05@mail.ru (M.A.M.); nmamadalieva@yahoo.com (N.Z.M.); \\ salima_aripova@mail.ru (S.F.A.) \\ 3 Department of Bioorganic Chemistry, Leibniz Institute of Plant Biochemistry, Weinberg 3, \\ D-06120 Halle (Saale), Germany \\ 4 Department of Biology, Science Faculty, Selcuk University, 42130 Konya, Turkey; \\ gokhanzengin@selcuk.edu.tr \\ 5 Department of Pharmacy Practice, College of Pharmacy, Princess Nourah bint Abdulrahman University, \\ Riyadh 11671, Saudi Arabia; ejalshammari@pnu.edu.sa \\ * Correspondence: ashour@pharma.asu.edu.eg; Tel.: +20-10-68-222-354; Fax: +20-22-405-1107
}

Received: 22 July 2020; Accepted: 12 August 2020; Published: 14 August 2020

Abstract: The differences in the composition of essential oils obtained from the aerial parts of six Ferula species viz., F. caratavica $(F c), F$. kuchistanica $(F k), F$. pseudoreoselinum ( $F p)$, F. samarcandica $(F s)$, F. tenuisecta $(F t)$ and $F$. varia $(F v)$ were detected both qualitatively and semi-quantitatively using GC-MS and GC-FID analyses. One hundred and six metabolites were identified that account for 92.1, 96.43, $87.43,95.95,92.90$ and $89.48 \%$ of $F c, F k, F p, F s, F t$ and $F v$ whole essential oils, respectively. The data from the GC-MS analyses were subjected to unsupervised pattern recognition chemometric analysis utilizing principal component analysis (PCA) to improve the visualization of such differences among the six species. $F k$ and $F t$ are very closely related to each other and were gathered together in one cluster. The antioxidant potential was assessed in vitro using different assays including 2,2'-azino-bis (3-ethylbenzothiazoline-6-sulphonic acid) (ABTS), cupric reducing antioxidant capacity (CUPRAC), ferric reducing power (FRAP) and phosphomolybdenum (PM) assays. Ft and Fp exhibited the most notable antioxidant properties as evidenced by their pronounced activities in most of the antioxidant assays performed, followed by $F c$. Fk showed the most effective tyrosinase inhibitory potential, which was estimated as $119.67 \mathrm{mgKAE} / \mathrm{g}$ oil, while $\mathrm{Fp}$ exhibited the most potent $\alpha$-amylase inhibitory potential, which was equivalent to $2.61 \mathrm{mmol} \mathrm{ACAE/g} \mathrm{oil.} \mathrm{Thus,} \mathrm{it} \mathrm{was} \mathrm{concluded} \mathrm{that} \mathrm{Ferula} \mathrm{species}$ could serve as a promising natural antioxidant drug that could be included in different products and spices to alleviate hyperglycemia and used as a natural ingredient in pharmaceutical cosmetics to counteract hyperpigmentation.

Keywords: Ferula; GC; essential oils; chemometrics; antioxidant activity; enzyme inhibition

\section{Introduction}

Essential oils comprise a mixture of secondary metabolites, which are biosynthesized by aromatic plants as natural protectants [1]. The role of essential oils is not restricted to protection as they also 
offer many therapeutic benefits to humans that can exceed the benefits provided by the dried herbs on their own [2]. Recently, they have become well known as a part of traditional medicine for the treatment of a plethora of human ailments, in aromatherapy, as well as in spices with high nutritive value [3]. In addition, many essential oils as well as plant extracts have shown significant antioxidant potential [4-6]. New sources of medicinal agents that are effective and safe as well as selective has recently become the main target in drug discovery. Medicinal plants in general, and their volatile constituents in particular, act as a very important sources for the production of a huge number of biologically active agents, which are attractive chemical leads that are promising therapeutic agents for the alleviation of many ailments [7,8]. Many biological activities have been ascribed to the volatile constituents obtained from a variety of plants such as antinociceptive, anticancer, antiphlogistic, antiviral, antioxidant, antimicrobial, antimycotic, antiparasitic and insecticidal activities [9]. Moreover, the volatile constituents of plants are highly popular in the food, cosmetic and pharmaceutical industries because of their broad acceptance by consumers, relative safety, and their potential multipurpose effect $[10,11]$.

The Apiaceae family is well-known for its rich aromatic plants, which are categorized under approximately 112 genera and nearly 316 species. Anise, chervil, celery, coriander, cumin, caraway, dill, fennel, ferula and galabanum are significant members of this family and they are characterized by their notable odor owing to the presence of considerable amounts of essential oils or the oleoresin predominant in their different organs [3]. These plants are widely used for culinary purposes either for their aroma or as nutrients [12].

Ferula constitutes the third largest genus in the Apiaceae family with nearly 180 species. The members of this genus are very popular for their essential oils, which are recognized as having many biological activities including antibacterial, antifungal, antiviral, antispasmodic, anticonvulsant, and antioxidant activity as well as having high nutritive value $[13,14]$.

This study aimed to investigate the contents of the essential oil from six Ferula species growing in Uzbekistan, namely, F. caratavica $(F c)$, F. kuchistanica $(F k), F$. pseudoreoselinum ( $F p)$, F. samarcandica $(F s)$, F. tenuisecta $(F t)$ and F. varia $(F v)$ using GC analyses. Discrimination of these species was carried by coupling the data obtained from GC-analyses with chemometrics employing unsupervised pattern recognition techniques represented by principal component analysis (PCA). Furthermore, the antioxidant potential of the different essential oil samples using different assays, namely, 2,2'-azino-bis (3-ethylbenzothiazoline-6-sulphonic acid) (ABTS), cupric reducing antioxidant capacity (CUPRAC), ferric reducing power (FRAP), and the phosphomolybdenum (PM) assay were evaluated in vitro. In addition, an evaluation of the possible enzymatic inhibitory activities of essential oils against tyrosinase and $\alpha$-amylase was done using standard in vitro bioassays.

\section{Results and Discussion}

\subsection{Qualitative and Semi-quantitative Determinations by GC-MS and GC-FID}

The differences in the composition of the essential oils obtained from the aerial parts of $F c, F k$, $F p, F s, F t$ and $F v$ were detected both qualitatively and semi-quantitatively using GC-MS and GC-FID analyses, respectively. All of the essential oils are yellow in color and possess a characteristic odor. Characterization of the essential oils using GC analyses revealed the presence of 106 metabolites (Table 1, Figures 1 and 2) that account for $92.10,96.43,87.43,95.95,92.90$ and $89.48 \%$ of $F c, F k, F p$, $F s, F t$ and $F v$ whole essential oils, respectively. Twenty-nine compounds were detected in $F c$ with $\alpha$-pinene (21.17\%), 10,13 docosadienoic acid methyl ester (15.20\%), $\beta$-caryophyllene oxide $(13.23 \%)$ and caryophyllene $(10.88 \%)$ representing the predominant compounds. Meanwhile, thirty-nine compounds were identified in $F k$ essential oil with $\alpha$-pinene (36.79\%) and verbenol $(8.49 \%)$ being the major compounds. In $F p$, forty-five compounds were characterized with 4-terpineol (16.28\%), $\alpha$-pinene $(10.99 \%), \beta$-myrcene $(6.04 \%), \beta$-caryophyllene oxide $(5.69 \%)$, p-cymen-8-ol $(5.36 \%)$ and spathulenol $(5.34 \%)$ as the main metabolites in the oil. Furthermore, 15 compounds were determined in Fs oil with 
the main compounds, palmitic acid, $\beta$-myrecene, heptacosane, octacosane, hexacosane and pentcosane accounting for $39.09,10.75,10.27,9.60,8.99$ and $6.29 \%$, respectively. For $F t, 62$ compounds were detected of which $\alpha$-pinene (42.0\%), camphene (8.34\%) and $\alpha$-cadinol $(8.14 \%)$ exist in high percentages in the oil. Finally, 25 compounds were identified in the $F v$ oil with 10,13 docosadienoic acid methyl ester $(69.61 \%)$ constituting the major component (Figure 3). From the data shown in Table 1, it was concluded that monoterpenes are the predominate class of essential oil metabolites in $F c$, $F k$ and $F t$, where they represents $24.90,42.91$ and $61.95 \%$, respectively, while oxygenated monoterpenes are the dominant class of metabolites in $F p(35.60 \%)$, and they also exist in a high percentage in $F k(34.82 \%)$. On the contrary, fatty acids are highly predominate in $F s$ and $F v$ and account for 82.55 and $79.84 \%$, respectively.

Table 1. Composition of volatile oil in the aerial parts of $F$. caratavica $(F c)$, F. kuchistanica $(F k)$, F. pseudoreoselinum (Fp), F. samarcandica (Fs), F. tenuisecta $(F t)$ and F. varia $(F v)$.

\begin{tabular}{|c|c|c|c|c|c|c|c|c|c|c|}
\hline \multicolumn{2}{|r|}{ Compound } & \multicolumn{2}{|c|}{ RI } & \multicolumn{6}{|c|}{ Content, (\%) } & \multirow{2}{*}{ Identification Methods } \\
\hline & & Cal. & Rep. & $F c$ & $F k$ & $F p$ & Fs & $F t$ & $F v$ & \\
\hline 1. & n-Nonane & 889 & 900 & 0.37 & - & 0.16 & - & - & - & MS, RI, \\
\hline 2. & Tricyclene & 913 & 913 & - & - & - & - & 0.37 & - & MS, RI, \\
\hline 3. & 3-Thujene & 919 & 919 & - & - & 0.50 & - & 0.36 & - & MS, RI, AU \\
\hline 4. & $\alpha$-Pinene & 925 & 925 & 21.17 & 36.79 & 10.99 & 1.5 & 42.0 & - & MS, RI, AU \\
\hline 5. & Camphene & 941 & 941 & 2.91 & 0.47 & - & - & 8.34 & - & MS, RI, \\
\hline 6. & Sabinene & 970 & 970 & - & - & 0.94 & - & 0.35 & - & MS, RI, \\
\hline 7. & $\beta$-Pinene & 973 & 973 & 0.82 & 1.88 & 3.11 & - & 3.59 & - & MS, RI, AU \\
\hline 8. & 6-Methyl-5-heptene-2-one & 986 & 986 & - & 0.35 & - & - & - & - & MS, RI, AU \\
\hline 9. & $\beta$-Myrcene & 989 & 989 & - & 0.19 & 6.04 & 10.75 & 1.90 & - & MS, RI, \\
\hline 10. & n-Decane & 998 & 1000 & 1.00 & 0.16 & 0.47 & 2.44 & 0.06 & 0.62 & MS, RI, \\
\hline 11. & $\alpha$-Phellandrene & 1003 & 1003 & - & 1.81 & $\operatorname{tr}$ & - & - & - & MS, RI, AU \\
\hline 12. & (3E)-3-Hexenyl acetate & 1007 & 1006 & - & - & - & - & - & 1.40 & MS, RI, \\
\hline 13. & 3-Carene & 1009 & 1009 & - & $\operatorname{tr}$ & 0.97 & - & 0.07 & - & MS, RI, \\
\hline 14. & 2-Carene & 1016 & 1018 & - & - & $\operatorname{tr}$ & - & & - & MS, RI, \\
\hline 15. & $\beta$-Cymene & 1024 & 1025 & - & $\operatorname{tr}$ & 2.59 & - & 0.39 & - & MS, RI, \\
\hline 16. & Limonene & 1028 & 1028 & - & 1.77 & 0.83 & 1.15 & 4.80 & - & MS, RI, AU \\
\hline 17. & $\tau$-Terpinene & 1059 & 1059 & - & - & 0.30 & - & - & - & MS, RI, AU \\
\hline 18. & Linalool oxide & 1074 & 1074 & - & 0.25 & - & - & - & - & MS, RI, \\
\hline 19. & Terpinolene & 1089 & 1089 & - & - & - & - & $\operatorname{tr}$ & - & MS, RI, \\
\hline 20. & Dehydro-p-cymene & 1090 & 1090 & - & - & - & - & 0.15 & - & MS, RI, \\
\hline 21. & n-Undecane & 1098 & 1100 & $\operatorname{tr}$ & 1.60 & - & 1.56 & - & 0.43 & MS, RI, \\
\hline 22. & $\beta$-Linalool & 1100 & 1100 & $\operatorname{tr}$ & $\operatorname{tr}$ & 2.03 & - & 0.54 & - & MS, RI, AU \\
\hline 23. & cis-p-Menth-2,8-dienol & 1108 & 1104 & - & 0.80 & 1.78 & - & 0.40 & - & MS, RI, \\
\hline 24. & Fenchol & 1116 & 1117 & - & - & - & - & 0.04 & - & MS, RI, \\
\hline 25. & 6-Camphenol & 1128 & 1131 & - & 2.75 & & - & 0.05 & - & MS, RI, \\
\hline 26. & Limonene oxide & 1135 & 1133 & - & - & - & - & $\operatorname{tr}$ & - & MS, RI, \\
\hline 27. & 4-Isopropenyl-1-methyl-2-cyclohexen-1-ol & 1137 & 1142 & - & 0.32 & 0.49 & - & 0.12 & - & MS, RI, \\
\hline 28. & L-pinocarveol & 1141 & 1141 & - & 3.90 & 0.74 & - & 0.33 & - & MS, RI, \\
\hline 29. & Verbenol & 1148 & 1148 & - & 8.49 & - & - & 1.25 & - & MS, RI, \\
\hline 30. & trans-2-Nonenal & 1160 & 1161 & - & - & - & - & 0.03 & 0.73 & MS, RI, \\
\hline 31. & 3-Pinanone & 1163 & 1160 & - & $\operatorname{tr}$ & - & - & - & - & MS, RI, \\
\hline 32. & Verbenone & 1165 & 1173 & - & 1.43 & - & - & - & - & MS, RI, \\
\hline 33. & Borneol & 1169 & 1169 & - & - & - & - & 0.11 & - & MS, RI, \\
\hline 34. & 4-Terpineol & 1179 & 1179 & - & 0.39 & 16.28 & - & 0.36 & - & MS, RI, \\
\hline 35. & p-Cymen-8-ol & 1186 & 1186 & $\operatorname{tr}$ & 2.85 & 5.36 & - & 0.80 & 0.49 & MS, RI, \\
\hline 36. & $\alpha$-Terpineol & 1193 & 1193 & - & 0.52 & 5.00 & - & 0.41 & - & MS, RI, \\
\hline 37. & Myrtenol & 1199 & 1199 & - & 2.30 & 0.65 & - & 0.21 & - & MS, RI, \\
\hline 38. & cis-Geraniol & 1210 & 1210 & - & - & 0.35 & - & $\operatorname{tr}$ & - & MS, RI, \\
\hline 39. & Verbenone & 1214 & 1214 & - & 3.95 & 1.11 & - & 0.18 & - & MS, RI, \\
\hline 40. & Fenchyl acetate & 1222 & 1223 & - & 4.51 & - & - & - & - & MS, RI, \\
\hline 41. & cis-Carveol & 1225 & 1220 & - & $\operatorname{tr}$ & - & - & 0.46 & - & MS, RI, \\
\hline 42. & $\beta$-Citronellol & 1230 & 1230 & - & - & - & - & 0.05 & - & MS, RI, \\
\hline 43. & trans-Carveol & 1234 & 1229 & - & - & - & - & 0.04 & - & MS, RI, \\
\hline 44. & Thymol methyl ether & 1237 & 1237 & - & 0.19 & 0.23 & - & 0.03 & - & MS, RI, \\
\hline 45. & D-Carvone & 1249 & 1249 & - & 1.68 & - & - & $\operatorname{tr}$ & - & MS, RI, \\
\hline
\end{tabular}


Table 1. Cont.

\begin{tabular}{|c|c|c|c|c|c|c|c|c|c|c|}
\hline \multirow{2}{*}{\multicolumn{2}{|c|}{ Compound }} & \multicolumn{2}{|c|}{ RI } & \multicolumn{6}{|c|}{ Content, $(\%)$} & \multirow{2}{*}{ Identification Methods } \\
\hline & & Cal. & Rep. & $F c$ & $F k$ & $F p$ & Fs & Ft & $F v$ & \\
\hline 46. & Nerol & 1252 & 1251 & - & $\operatorname{tr}$ & - & - & $\operatorname{tr}$ & - & MS, RI, \\
\hline 48. & (-)-trans-Pinocarvyl acetate & 1305 & 297 & - & - & 1.19 & - & - & - & MS, RI, \\
\hline 49. & Carvacrol & 1306 & 1306 & - & $\operatorname{tr}$ & - & - & - & - & MS, RI, \\
\hline 50. & $\alpha$-Cubebene & 1353 & 1353 & - & - & - & - & 0.16 & - & MS, RI, \\
\hline 51. & D-longifolene & 1370 & 1370 & - & $\operatorname{tr}$ & - & - & - & - & MS, RI, \\
\hline 54. & $\beta$-Bourbonene & 1390 & 1390 & - & - & - & - & - & $\operatorname{tr}$ & MS, RI, \\
\hline 55. & $\beta$-Elemene & 1395 & 1395 & - & - & - & - & 0.24 & $\operatorname{tr}$ & MS, RI, \\
\hline 56. & Jasmone & 1403 & 1399 & - & $\operatorname{tr}$ & - & - & - & - & MS, RI, \\
\hline 57. & $\beta$-Caryophyllene & 1425 & 1425 & 10.88 & - & 0.91 & - & 0.08 & $\operatorname{tr}$ & MS, RI, AU \\
\hline 58. & $\tau$-Elemene & 1438 & 1438 & - & - & - & - & 0.12 & - & MS, RI, \\
\hline 59. & Patchoulene & 1440 & 1440 & $\operatorname{tr}$ & - & 0.38 & - & & - & MS, RI, \\
\hline 64. & $\alpha$-Curcumene & 1487 & 1486 & - & $\operatorname{tr}$ & - & - & & - & MS, RI, \\
\hline 65. & Germacrene D & 1489 & 1489 & - & - & - & - & 0.13 & - & MS, RI, \\
\hline 66. & $\beta$-Eudesmene & 1495 & 1495 & - & - & - & - & 0.20 & - & MS, RI, \\
\hline 67. & $\beta$-Guaiene & 1503 & 1500 & 0.65 & - & $\operatorname{tr}$ & - & 0.38 & $\operatorname{tr}$ & MS, RI, \\
\hline 68. & $\alpha$-Muurolene & 1508 & 1508 & - & - & 0.35 & - & 0.74 & - & MS, RI, \\
\hline 69. & Cuparene & 1514 & 1513 & 3.09 & 0.23 & - & - & - & - & MS, RI, \\
\hline 70. & $\alpha$-Selinene & 1514 & 1517 & - & $\operatorname{tr}$ & - & - & 0.07 & 0.34 & MS, RI, \\
\hline 71. & $\tau$-Cadinene & 1523 & 1521 & - & - & - & - & 0.75 & 0.50 & MS, RI, \\
\hline 72. & $\beta$-Cadinene & 1524 & 1529 & $\operatorname{tr}$ & - & - & - & - & - & MS, RI, \\
\hline 73. & $\delta$-Cadinene & 1531 & 1531 & 1.37 & - & - & $\operatorname{tr}$ & 3.07 & - & MS, RI, \\
\hline 74. & Elemol & 1557 & 1577 & - & - & - & - & $\operatorname{tr}$ & - & MS, RI, \\
\hline 75. & Nerolidol & 1566 & 1564 & 1.70 & - & - & - & 1.74 & - & MS, RI, \\
\hline 76. & Germacrene B & 1572 & 1569 & - & - & - & - & - & 1.07 & MS, RI, \\
\hline 85. & $\tau$-Muurolol & 1652 & 1652 & 2.03 & - & - & $\operatorname{tr}$ & 3.49 & 1.02 & MS, RI, \\
\hline 86. & $\delta$-Cadinol & 1656 & 1656 & $\operatorname{tr}$ & 2.82 & - & $\operatorname{tr}$ & 0.79 & - & MS, RI, \\
\hline 87. & $\tau$-Muurolol & 1665 & 1661 & 4.64 & - & - & - & & - & MS, RI, \\
\hline 88. & $\alpha$-Eudesmol & 1666 & 1662 & - & 2.54 & - & - & & 1.01 & MS, RI, \\
\hline 89. & $\alpha$-Cadinol & 1669 & 1669 & - & - & - & - & 8.14 & - & MS, RI, \\
\hline 90. & Cedr-8-en-13-ol & 1682 & 1688 & 2.17 & - & - & - & & - & MS, RI, \\
\hline 91. & $\alpha$-Bisabolol & 1692 & 1692 & - & - & - & - & 0.56 & - & MS, RI, \\
\hline 92. & Farnesol & 1726 & 1725 & 0.82 & - & - & - & 1.13 & - & MS, RI, \\
\hline 93. & Hexadecanal & 1817 & 1819 & - & - & - & - & - & 1.16 & MS, RI, \\
\hline 94. & Hexahydrofarnesyl acetone & 1845 & 1845 & - & $\operatorname{tr}$ & - & - & - & - & MS, RI, \\
\hline 95. & Palmitic acid & 1977 & 1975 & - & - & - & 39.03 & - & - & MS, RI, AU \\
\hline 96. & trans-9-Octadecen-1-ol & 2068 & 2068 & - & - & 1.31 & - & - & - & MS, RI, \\
\hline 97. & Heptadecanoic acid ethyl ester & 2082 & 2082 & 1.06 & - & - & - & - & - & MS, RI, \\
\hline 98. & trans-Phytol & 2120 & 2122 & 2.69 & - & 0.42 & - & - & - & MS, RI, \\
\hline 99. & Docosane & 2200 & 2200 & - & - & 0.60 & 1.47 & - & - & MS, RI, \\
\hline 100. & Tricosane & 2301 & 2300 & - & - & 0.34 & $\operatorname{tr}$ & - & 2.66 & MS, RI, \\
\hline 101. & Tetracosane & 2395 & 2400 & - & - & 0.51 & 4.49 & - & - & MS, RI, \\
\hline 102. & 10,13 Docosadienoic acid methyl ester & 2449 & 2449 & 15.2 & - & - & - & - & 69.61 & MS, RI, \\
\hline 103. & Pentacosane & 2498 & 2500 & 0.66 & - & 0.95 & 6.26 & - & - & MS, RI, \\
\hline 104. & Hexacosane & 2598 & 2600 & 0.63 & - & 1.10 & 8.99 & - & 3.23 & MS, RI, \\
\hline 105. & Heptacosane & 2697 & 2700 & 1.26 & - & 1.35 & 10.27 & - & - & MS, RI, \\
\hline \multirow[t]{4}{*}{106.} & Octacosane & 2790 & 2800 & 0.77 & - & 1.13 & 9.60 & - & $\operatorname{tr}$ & MS, RI, \\
\hline & Monoterpene hydrocarbons & & & 24.9 & 42.91 & 26.27 & 13.40 & 61.95 & - & \\
\hline & Oxygenated monoterpene & & & $\operatorname{tr}$ & 34.82 & 35.60 & - & 5.69 & 0.49 & \\
\hline & Sesquiterpene hydrocarbons & & & 18.97 & 5.69 & 2.05 & $\operatorname{tr}$ & 6.37 & 3.80 & \\
\hline
\end{tabular}

Compounds were identified based on a comparison of the compounds' mass spectral data and retention indices with those of the NIST Mass Spectral Library (December 2011), the Wiley Registry of Mass Spectral Data, 8th edition and by comparison with the authentic standard (AU). The content (\%) was calculated using the normalization method based on the GC-FID data generated from the average of three independent chromatographic runs. 

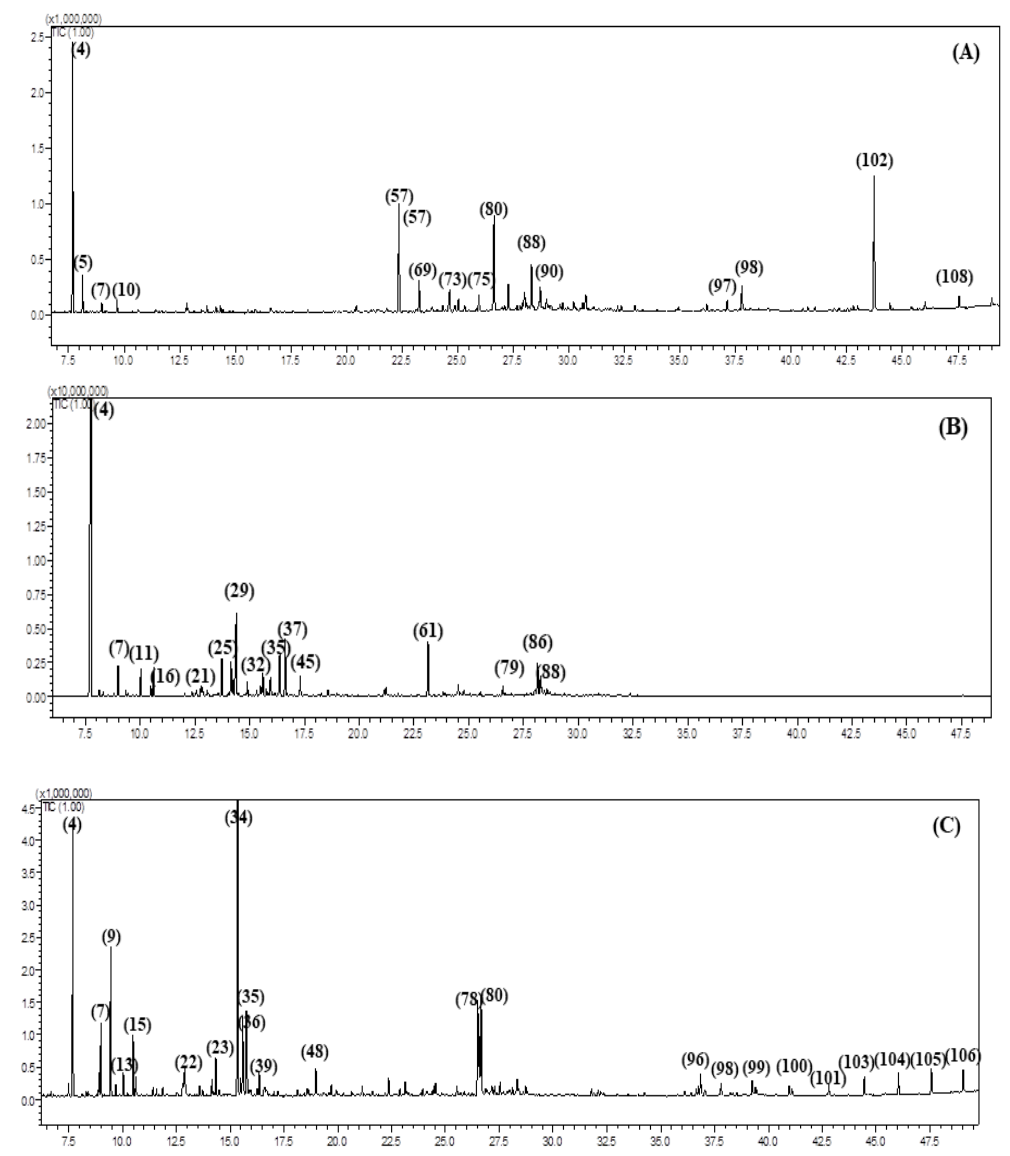

Figure 1. GC-MS chromatograms of F. caratavica (A), F. kuchistanica (B) and F. pseudoreoselinum (C).
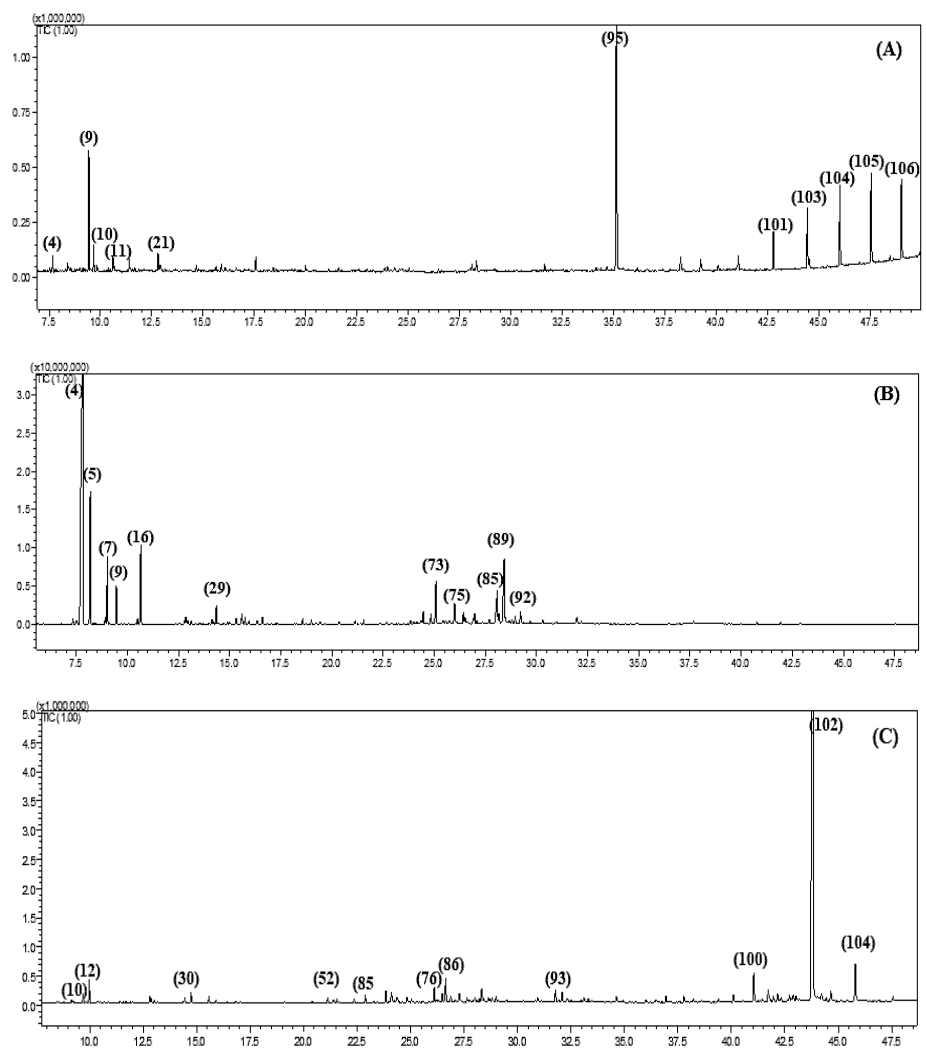

Figure 2. GC-MS chromatograms of F. samarcandica (A), F. tenuisecta (B) and F. varia (C). 


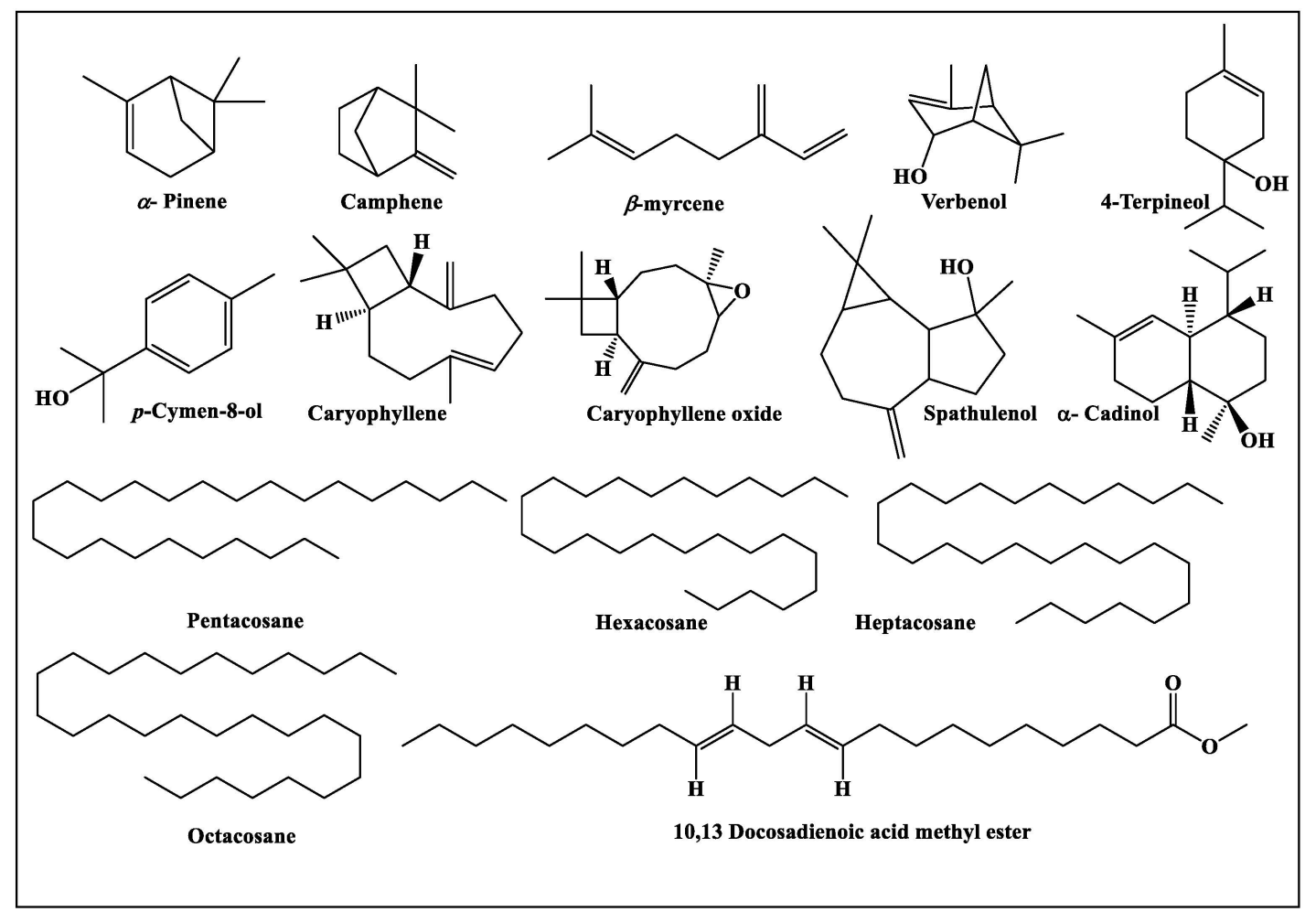

Figure 3. Main secondary metabolites in the Ferula species.

\subsection{Chemometric Analysis}

It is extremely difficult to identify the qualitative and quantitative differences between the Ferula species under evaluation with the naked eye. So, the data obtained from GC analyses were subjected to unsupervised pattern recognition chemometric analysis utilizing PCA to improve the visualization of these differences. The results of the PCA, as represented by the obtained score plot shown in Figure 4A effectively discriminated the six Ferula species into five clusters along the first component (PC1) and the second component (PC2) that account for $57 \%$ and $30 \%$, respectively, or $87 \%$ of the total variance. From the obtained results, it is obvious that both $F k$ and $F t$ are very closely related to each other as they are gathered together in one cluster in the lower left quadrant. However, PC1 successfully discriminated between $F k$ and $F t$ with negative values of $P C 1$ as they are located in the lower left quadrant and $F_{C}$ and $F v$, which show positive values of PC1 are located in the lower right quadrant. Meanwhile, PC2 significantly discriminated between $F k$ and $F t$, which show negative values of PC2 as they are located in the lower left quadrant and between $F s$ and $F p$, which show positive values of PC2 and are located in the upper left quadrant. Furthermore, both PC1 and PC2 significantly discriminated between $F c$ and $F v$, which show positive values for PC1 and negative values for PC2 as they are located in the lower right quadrant and between $F s$ and $F p$, displaying negative values for PC1 and positive values for PC2 as they are located in the upper left quadrant. The major discriminatory signals are $\alpha$-pinene, 10,13-docosadienoic acid methyl ester and palmitic acid as revealed in the loading plot shown in Figure 4B.

The Pearson correlation coefficient (r) between the essential oil contents of different studied samples indicated that $F c$ had a highly significant positive correlation with $F t(\mathrm{r}=0.71), F k(\mathrm{r}=0.58)$, $F v(\mathrm{r}=0.47)$ and $F p(\mathrm{r}=0.35)$, while a non-significant negative correlation was observed between $F c$ and $F s$ (the highest correlations were observed between $F t$ and $F k(r=0.89, p<0.001)$, between $F c$ and $F t(r=0.71, p<0.001)$, and between $F c$ and $F k(r=0.58, p<0.001)$ as seen in Table 2. These data indicate that three samples, $F t, F k$, and $F c$ have highly similar essential oil content. 


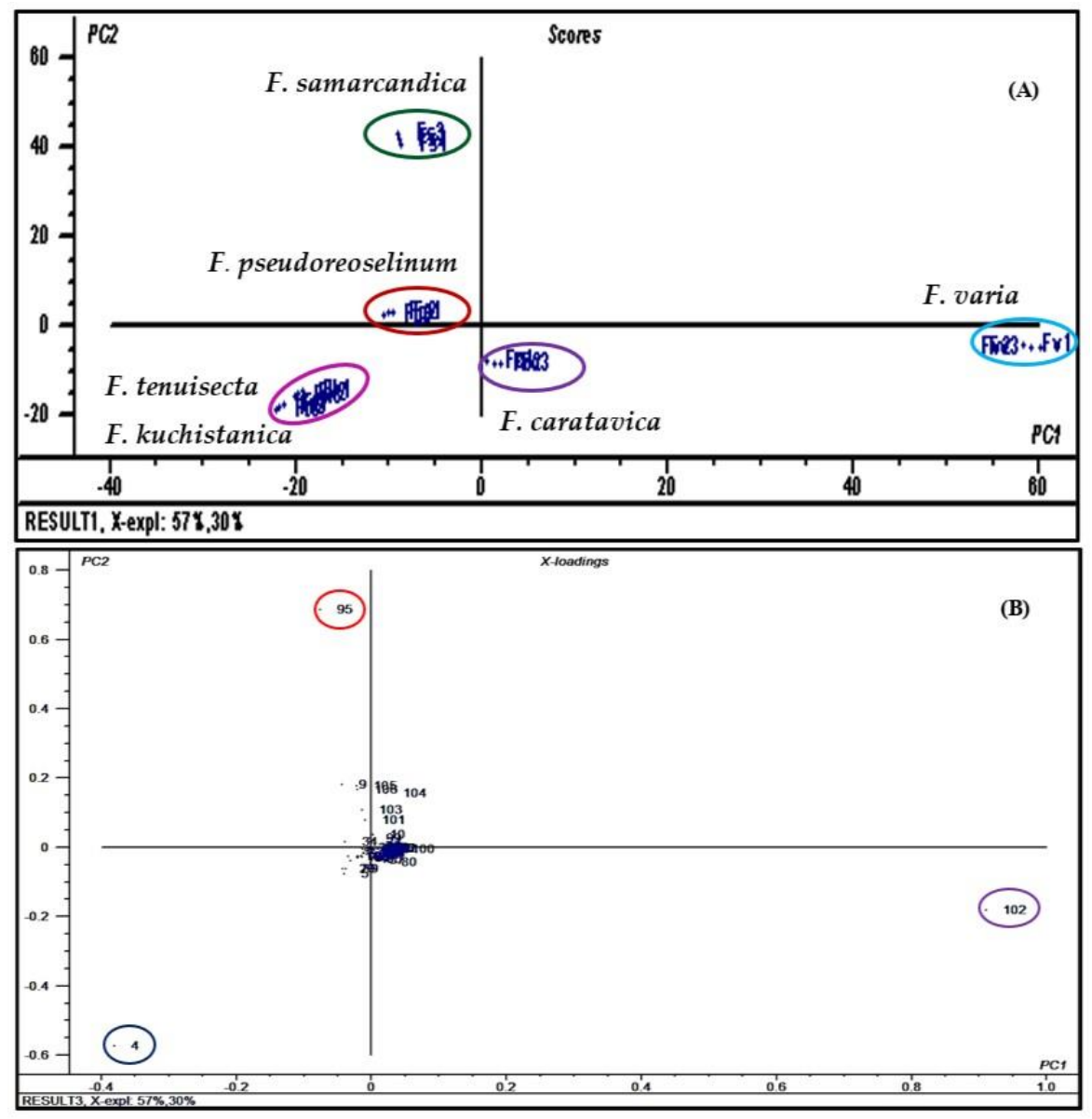

Figure 4. Score plot (A) and loading plot (B) of GC data obtained from F. caratavica, F. kuchistanica, F. pseudoreoselinum, F. samarcandica, F. tenuisecta and F. varia essential oil analyses using principal component analysis (PCA). In the loading plot, compounds are given numbers as in Table 1 where the major discriminatory signals are $\alpha$-pinene (4), palmitic acid (95) and 10,13-docosadienoic acid methyl ester (102).

Table 2. The Pearson correlation matrix of the essential oils content of different samples.

\begin{tabular}{ccccccc}
\hline & $\boldsymbol{F c}$ & $\boldsymbol{F k}$ & $\boldsymbol{F p}$ & $\boldsymbol{F s}$ & $\boldsymbol{F t}$ & $\boldsymbol{F v}$ \\
\hline $\boldsymbol{F c}$ & - & $0.58^{* * *}$ & $0.35^{* * *}$ & -0.02 & $0.71^{* * *}$ & $0.47^{* * *}$ \\
\hline $\boldsymbol{F} \boldsymbol{k}$ & $0.58^{* * *}$ & - & $0.43^{* * *}$ & -0.02 & $0.89^{* * *}$ & -0.03 \\
\hline $\boldsymbol{F} \boldsymbol{p}$ & $0.35^{* * *}$ & $0.43^{* * *}$ & - & 0.05 & $0.45^{* * *}$ & -0.03 \\
\hline $\boldsymbol{F} \boldsymbol{s}$ & -0.02 & -0.02 & 0.05 & - & -0.002 & -0.02 \\
\hline $\boldsymbol{F t}$ & $0.71^{* * *}$ & $0.89^{* * *}$ & $0.45^{* * *}$ & -0.002 & - & -0.03 \\
\hline $\boldsymbol{F v}$ & $0.47^{* * *}$ & -0.03 & -0.03 & -0.02 & -0.03 & -
\end{tabular}

The data is represented as the $\mathrm{r}$ value of the correlation coefficient and ${ }^{* * *}$ is the level of significance, $p<0.001$.

\subsection{Biological Evaluation}

\subsubsection{Antioxidant Potential of Different Ferula Species}

The antioxidant potential of the different essential oil samples was performed in vitro using the 2,2'-azino-bis(3-ethylbenzothiazoline-6-sulfonic acid) (ABTS), the cupric ion reducing antioxidant capacity (CUPRAC), The ferric reducing antioxidant power (FRAP) and the phosphomolybdenum 
method (PM) assays. The results displayed in Table 3 reveal that most of the samples showed considerable antioxidant potential in the performed assays. $F c(41.36 \mathrm{mgTE} / \mathrm{g}$ oil) exhibited the most antioxidant activity in ABTS assays, followed by $F k(29.12 \mathrm{mgTE} / \mathrm{g}$ oil) and $F t$ ( $28.03 \mathrm{mgTE} / \mathrm{g}$ oil). However, in CUPRAC assay, $F p(289.45 \mathrm{mgTE} / \mathrm{g}$ oil) showed the most superior antioxidant potential followed by $F t$ ( $278.87 \mathrm{mgTE} / \mathrm{g}$ oil) and $F k$ (120.43 mgTE/g oil). Furthermore, Ft exhibited the most significant antioxidant power in both FRAP and PM assays with antioxidant activity equivalent to $136.81 \mathrm{mgTE} / \mathrm{g}$ oil and $78.66 \mathrm{mmolTE} / \mathrm{g}$ oil, respectively, followed by $F p$, which showed antioxidant potential of $121.64 \mathrm{mgTE} / \mathrm{g}$ oil and $50.86 \mathrm{mmolTE} / \mathrm{g}$ oil in FRAP and PM assays, respectively. Thus, it can be concluded that the essential oil from both $F t$ and $F p$ exhibited the most notable antioxidant properties as evidenced by their pronounced activities in most of the performed antioxidant assays, followed by $F c$. $\alpha$-Pinene, the predominant compound in $F t$ and $F p$ has previously been shown to possess notable antioxidant activity [15]. Additionally, the significant antioxidant activity found in this study, which can be interpreted as a result of the synergistic action between the different components that exist in the oils, was in accordance with that previously reported for many other Ferula species such as F. microcolea, F. orantalis and F. communis. Various mechanisms can be used to interpret antioxidant potential including the prohibition of chain initiation, peroxide decomposition, obstruction of continual hydrogen removal as well as the scavenging of free radical and uniting transition metal ion catalysts $[3,16,17]$. Additionally, $\alpha$-pinene, the main constituent in both $F t$ and $F p$, has previously been shown to be a potent antioxidant in both DPPH and FRAP assays, displaying $\mathrm{EC}_{50}$ values equal to 310 and $238 \mu \mathrm{g} / \mathrm{mL}$, respectively [18].

Table 3. Antioxidant activities of the essential oil samples of Ferula species using the 2,2'-azino-bis(3-ethylbenzothiazoline-6-sulfonic acid) (ABTS), the cupric ion reducing antioxidant capacity (CUPRAC), The ferric reducing antioxidant power (FRAP) and the phosphomolybdenum method (PM) assays.

\begin{tabular}{ccccc}
\hline Samples & ABTS $(\mathbf{m g T E} / \mathbf{g}$ Oil) & CUPRAC $(\mathbf{m g T E} / \mathbf{g}$ Oil) & FRAP $(\mathbf{m g T E} / \mathbf{g}$ Oil) & PM (mmolTE/g Oil) \\
\hline F. caratavica $(\mathrm{Fc})$ & $41.36 \pm 1.27^{\mathrm{a}}$ & $83.54 \pm 3.13^{\mathrm{c}}$ & $47.34 \pm 0.65^{\mathrm{e}}$ & $5.59 \pm 0.01^{\mathrm{f}}$ \\
F. kuchistanica $\left.^{\mathrm{F}} \mathrm{Fk}\right)$ & $29.12 \pm 0.85^{\mathrm{b}}$ & $120.43 \pm 9.36^{\mathrm{b}}$ & $80.74 \pm 0.25^{\mathrm{c}}$ & $36.42 \pm 0.07^{\mathrm{c}}$ \\
F. pseudoreoselinum $(\mathrm{Fp})$ & $22.68 \pm 1.03^{\mathrm{c}}$ & $289.45 \pm 7.30^{\mathrm{a}}$ & $121.64 \pm 0.01^{\mathrm{b}}$ & $50.86 \pm 0.07^{\mathrm{b}}$ \\
F. samarcandica $(\mathrm{Fs})$ & $11.84 \pm 1.37^{\mathrm{d}}$ & $74.39 \pm 4.73^{\mathrm{c}, \mathrm{d}}$ & $43.21 \pm 0.48^{\mathrm{f}}$ & $14.37 \pm 0.04^{\mathrm{e}}$ \\
F. tenuisecta $(\mathrm{Ft})$ & $28.03 \pm 3.89^{\mathrm{b}}$ & $278.87 \pm 8.51^{\mathrm{a}}$ & $136.81 \pm 1.98^{\mathrm{a}}$ & $78.66 \pm 0.15^{\mathrm{a}}$ \\
F. varia $(\mathrm{Fv})$ & $7.04 \pm 0.47^{\mathrm{e}}$ & $65.90 \pm 1.66^{\mathrm{d}}$ & $55.00 \pm 0.18^{\mathrm{d}}$ & $15.33 \pm 0.07^{\mathrm{d}}$ \\
\hline
\end{tabular}

Values are reported as mean \pm S.D of three parallel measurements. TE: Trolox equivalents. Different superscripts $(\mathrm{a}-\mathrm{f})$ indicate significant differences in the tested Ferula species $(p<0.05)$.

\subsubsection{Tyrosinase and $\alpha$-Amylase Inhibitory Potential}

Tyrosinase enzyme is an oxidase enzyme containing copper that assists in the completion of the first two steps of mammalian melanogenesis, which leads to undesirable hyperpigmentation. Thus, the search for effective tyrosinase inhibitors has recently become vital so that they can be incorporated in cosmetics for effective skin whitening and to counteract hyperpigmentation [19]. Fk showed the most effective tyrosinase inhibitory potential, which was estimated as $119.67 \mathrm{mgKAE} / \mathrm{g}$ oil followed by Fv, which showed an inhibitory potential equivalent to $118.42 \mathrm{mgKAE} / \mathrm{g}$ oil, where KAE is a Kojic acid equivalent, a potent tyrosinase inhibitory drug. Fv oil is rich in 10,13 docosadienoic acid methyl ester, a polyunsaturated fatty acid, which greatly accounts for its promise as a tyrosinase inhibitor [20]. The underlying tyrosinase inhibitory mechanism mainly relies on the essential oils being rich in components that possess a hydrophobic portion that competitively inhibits the active sites of tyrosinase enzyme with subsequent interference of melanin synthesis. This inhibition may be achieved via interaction with $\mathrm{Cu}^{+2}$ that exists in the active sites of tyrosinase in addition to the prohibition of tautomerization to dopachrome triggered by the oil, which behaves as a reducing agent and blocks of the oxidation reaction during the formation of melanin intermediates during the conversion of tyrosinase/DOPA into melanin, thus reducing skin pigmentation [21]. 
The $\alpha$-amylase enzyme is critical in assisting in the catalysis of the first steps in the conversion of starch into maltose, and subsequently to glucose [22,23]. Nowadays, $\alpha$-amylase inhibitors are used in therapeutic approaches to counteract hyperglycemia. Fp and Fv exhibited the most potent $\alpha$-amylase inhibitory potential as evidenced by their pronounced inhibitory activity, which was equivalent to 2.61 and $1.40 \mathrm{mmol}$ ACAE/g oil, respectively, in which ACAE is the acarbose equivalent, a potent $\alpha$-amylase inhibitor (Figure 5). 4-Terpineol as well as $\alpha$-pinene, which predominate the essential oil of $F p$, were previously reported to possess considerable $\alpha$-amylase inhibitory activity [24]. Similarly, the potent $\alpha$-amylase inhibitory potential is mainly due to the synergistic action between the different components, which is in accordance to different previously reported studies that confirmed the $\alpha$-amylase inhibitory effect of different terpenes and different Ferula species such as F. gummosa essential oil [24,25].
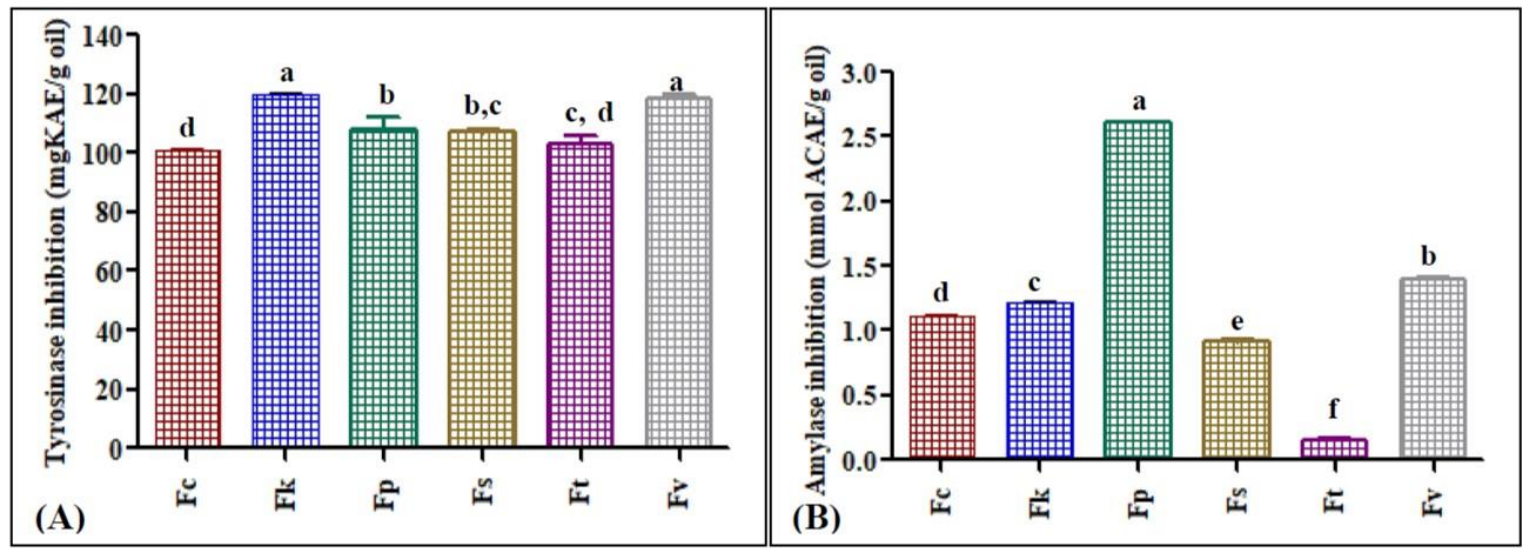

Figure 5. In vitro tyrosinase inhibition (A) and $\alpha$-amylase inhibition (B) of the essential oil of different Ferula species, F. caratavica $(F c)$, F. kuchistanica $(F k)$, F. pseudoreoselinum $(F p)$, F. samarcandica $(F s)$, F. tenuisecta $(F t)$ and F. varia $(F v)$. Different letters (a-f) indicate significant differences in the tested Ferula species $(p<0.05)$.

\section{Materials and Methods}

\subsection{Plant Material}

Aerial parts (flowers, leaves and stems) of F. caratavica Regel \& Schmalh (N2004), F. pseudoreoselinum (Regel \& Schmalh.) Koso-Pol., p.p. (N1489), F. tenuisecta Korovin (N1488) were collected from the Tashkent region of Uzbekistan. F. varia (Schrenk ex Fisch., C.A.Mey. \& Avé-Lall.) Trautv. (N1407) was collected from the Bukhara region (Uzbekistan), while F. kuchistanica Korovin (N1425) and F. samarcandica Korovin (N1919) were collected from the Samarkand region of Uzbekistan. The plants were collected during the flowering stage in June-July 2018. Their taxonomic authentication was accomplished by Dr. A. Nigmatullaev at the Institute of the Chemistry of Plant Substances (Tashkent, Uzbekistan).

\subsection{Preparation of Essential Oil Samples}

All the plant materials were air-dried in the shade for 7 days at room temperature and powdered using a mortar and pestle to get particles of a uniform, reduced size. Preparation of the essential oil samples was achieved by hydrodistillation of the air-dried aerial parts of the different Ferula species, F. caratavica $(F c)$, F. kuchistanica $(F k)$, F. pseudoreoselinum $(F p), F$. samarcandica $(F s)$, F. tenuisecta $(F t)$ and F. varia (Fv) for $2 \mathrm{~h}$ by Clevenger-type apparatus. Anhydrous $\mathrm{Na}_{2} \mathrm{SO}_{4}$ was used to dehydrate the prepared essential oils, yielding $0.4,0.7,0.3,0.3,0.8$ and $0.5 \% \mathrm{v} / \mathrm{w}$ of dry weight for $F c, F k, F p, F s, F t$ and $F v$, respectively. Then the various oil samples were maintained at $-30{ }^{\circ} \mathrm{C}$ in dark-colored stoppered glasses until their analyses [26,27]. 


\subsection{GC-FID and GC-MS Analyses}

A Shimadzu GC-17A gas chromatograph (Shimadzu Corporation, Kyoto, Japan) with an FID detector and DB-5 fused-bonded cap column (Phenomenex; $29 \mathrm{~m} \times 0.25 \mathrm{~mm}$ i.d., film thickness $0.25 \mu \mathrm{m}$; Torrance, California, USA) was utilized for the semi-quantitative determination of the different components of the essential oils using the normalization method to get the relative percentage of each component and applying GC-FID data that is highly sensitive using GC solution ${ }^{\circledR}$ software ver. 2.4 (Shimadzu Corporation, Kyoto, Japan). The areas under the peaks (AUP) were determined using three independent runs where the total area is considered as $100 \%$. Meanwhile, the Shimadzu GC-2010 plus gas chromatograph (Shimadzu Corporation, Kyoto, Japan) supplied with Rtx-5MS (Restek, Bellefonte, PA, USA) in addition to a quadrupole mass spectrometer was used for the identification of the essential oil different metabolites. Instrument settings were adjusted according to what was previously reported [28,29]. The Wiley Registry of Mass Spectral Data 8th edition, NIST MassSpectral Library (December 2011), and previously reported data were employed to confirm the identity of the compounds and the retention indexes were calculated to corroborate the identification of the volatile compounds [30,31].

\subsection{Chemometric and ANOVA Analysis}

To examine the differences between the essential oils' components prepared from different Ferula species, the data collected from the different GC-MS spectra were subjected to chemometric analysis of unsupervised pattern recognition represented by PCA, which was processed by employing Unscrambler 9.7 (CAMO SA, Oslo, Norway) [28,32]. Meanwhile, other statistical analyses used for biological assessment were performed using ANOVA assay (with Tukey's test, significant value: $p<$ 0.05) and Xlstat 2017 software.

\subsection{Biological Evaluation}

\subsubsection{Determination of the Antioxidant Potential}

The antioxidant activity of the different essential oil samples from different Ferula species was evaluated using ABTS, CUPRAC, FRAP and PM assays. These assays were performed following the methods described by Mamadalieva et al. [33]. The antioxidant activities were reported as Trolox equivalents and the samples were analyzed in triplicate.

\subsubsection{Determination of Enzyme Inhibitory Effects}

The possible inhibitory potential of the essential oil samples was investigated against tyrosinase and $\alpha$-amylase enzymes using standard in vitro bioassays as previously reported by Mamadalieva et al. [33] in which all the samples were analyzed in triplicate. Results are expressed in $\mathrm{mgKAE} / \mathrm{g}$ oil for tyrosinase inhibitory activity and in mmol ACAE/g oil for $\alpha$-amylase inhibition.

\section{Conclusions}

The essential oils obtained from different Ferula species, F. caratavica, F. kuchistanica, F. pseudoreoselinum, F. samarcandica, F. tenuisecta and F. varia showed significant variation as revealed by GC analyses. Furthermore, this variation became more clearly observable when coupled with a chemometric approach as represented by PCA used as an unsupervised pattern recognition technique. Additionally, the obtained essential oils showed notable antioxidant as well as tyrosinase and $\alpha$-amylase inhibitory activities with variable degrees, which is mainly related to the differences in the secondary metabolites that predominate in the oils. Thus, it was concluded that the different Ferula species could serve as a promising natural antioxidant drug that could be included in different products and used as spices to alleviate hyperglycemia and as a natural ingredient in pharmaceutical cosmetics to counteract hyperpigmentation. Chemometric study based on gathering the different biological activities of many 
additional Ferula species will be considered. It is recommended that further in vivo studies such as animal and bioavailability studies be carried out to confirm the obtained results.

Author Contributions: F.S.Y., identification of the essential oil compounds, chemometric analysis, writing the whole manuscript; M.A.M., N.Z.M., S.F.A., collection of the plants, isolation of the essential oil samples and revising the manuscript; G.Z., performing the biological studies; E.A. and M.L.A., supervising the study and revising the manuscript. All authors have read and agreed to the published version of the manuscript.

Funding: This research was funded by the Deanship of Scientific Research at Princess Nourah bint Abdulrahman University through the Fast-Track Research Funding Program.

Conflicts of Interest: The authors declare no conflict of interest.

\section{References}

1. Rehman, R.; Hanif, M.A.; Mushtaq, Z.; Al-Sadi, A.M. Biosynthesis of essential oils in aromatic plants: A review. Food Rev. Int. 2016, 32, 117-160. [CrossRef]

2. Sharifi-Rad, J.; Sureda, A.; Tenore, G.C.; Daglia, M.; Sharifi-Rad, M.; Valussi, M.; Tundis, R.; Sharifi-Rad, M.; Loizzo, M.R.; Ademiluyi, A.O. Biological activities of essential oils: From plant chemoecology to traditional healing systems. Molecules 2017, 22, 70. [CrossRef] [PubMed]

3. Sahebkar, A. Biological activities of essential oils from the genus Ferula (Apiaceae). Asian Biomed. Res. Rev. News. 2010, 4, 835-847. [CrossRef]

4. Burits, M.; Bucar, F. Antioxidant activity of Nigella sativa essential oil. Phytother. Res. 2000, 14, $323-328$. [CrossRef]

5. Koleva, I.I.; Van Beek, T.A.; Linssen, J.P.; Groot, A.d.; Evstatieva, L.N. Screening of plant extracts for antioxidant activity: A comparative study on three testing methods. Phytochem. Anal. 2002, 13, 8-17. [CrossRef]

6. Lee, S.E.; Hwang, H.J.; Ha, J.-S.; Jeong, H.-S.; Kim, J.H. Screening of medicinal plant extracts for antioxidant activity. Life Sci. 2003, 73, 167-179. [CrossRef]

7. Moniruzzaman; Shahinuzzaman; Haque, A.; Khatun, R.; Yaakob, Z. Gas chromatography mass spectrometry analysis and in vitro antibacterial activity of essential oil from Trigonella foenum-graecum. Asian Pac. J. Trop. Biomed. 2015, 5, 1033-1036. [CrossRef]

8. Rashid, S.; Rather, M.A.; Shah, W.A.; Bhat, B.A. Chemical composition, antimicrobial, cytotoxic and antioxidant activities of the essential oil of Artemisia indica Willd. Food Chem. 2013, 138, 693-700. [CrossRef]

9. Adorjan, B.; Buchbauer, G. Biological properties of essential oils: An updated review. Flav. Frag. J. 2010, 25, 407-426. [CrossRef]

10. Sun, J.; Wang, X.; Wang, P.; Li, L.; Qu, W.; Liang, J. Antimicrobial, antioxidant and cytotoxic properties of essential oil from Dictamnus angustifolius. J. Ethnopharmacol. 2015, 159, 296-300. [CrossRef]

11. Martins, C.D.M.; Nascimento, E.A.D.; de Morais, S.A.; de Oliveira, A.; Chang, R.; Cunha, L.; Martins, M.M.; Martins, C.H.G.; Moraes, T.D.S.; Rodrigues, P.V. Chemical constituents and evaluation of antimicrobial and cytotoxic activities of Kielmeyera coriacea Mart. \& Zucc. essential oils. Evid.-Based Complement. Altern. Med. 2015, 2015, 842047.

12. Safari, O.; Sarkheil, M.; Paolucci, M. Dietary administration of Ferula (Ferula asafoetida) powder as a feed additive in diet of koi carp, Cyprinus carpio koi: Effects on hemato-immunological parameters, mucosal antibacterial activity, digestive enzymes, and growth performance. Fish. Physiol. Biochem. 2019, 45, 1277-1288. [CrossRef] [PubMed]

13. Mohammadhosseini, M.; Venditti, A.; Sarker, S.D.; Nahar, L.; Akbarzadeh, A. The genus Ferula: Ethnobotany, phytochemistry and bioactivities-A review. Ind. Crops Prod. 2019, 129, 350-394. [CrossRef]

14. Iranshahy, M.; Iranshahi, M. Traditional uses, phytochemistry and pharmacology of Asafoetida (Ferula assafoetida oleo-gum-resin)—A review. J. Ethnopharmacol. 2011, 134, 1-10. [CrossRef] [PubMed]

15. Him, A.; Ozbek, H.; Turel, I.; Oner, A.C. Antinociceptive activity of alpha-pinene and fenchone. Pharmacologyonline 2008, 3, 363-369.

16. Amiri, H. Chemical composition and antioxidant activity of essential oil and methanolic extracts of Ferula microcolea (Boiss.) Boiss (Apiaceae). Int. J. Food Prop. 2014, 17, 722-730. [CrossRef] 
17. Nguir, A.; Mabrouk, H.; Douki, W.; Ismail, M.B.; Jannet, H.B.; Flamini, G. Chemical composition and bioactivities of the essential oil from different organs of Ferula communis L. growing in Tunisia. Med. Chem. Res. 2016, 25, 515-525. [CrossRef]

18. Bouzenna, H.; Hfaiedh, N.; Giroux-Metges, M.-A.; Elfeki, A.; Talarmin, H. Potential protective effects of alpha-pinene against cytotoxicity caused by aspirin in the IEC-6 cells. Biomed. Pharmacother. 2017, 93, 961-968. [CrossRef]

19. Chang, T.-S. An updated review of tyrosinase inhibitors. Int. J. Mol. Sci. 2009, 10, 2440-2475. [CrossRef]

20. Guo, Y.-J.; Pan, Z.-Z.; Chen, C.-Q.; Hu, Y.-H.; Liu, F.-J.; Shi, Y.; Yan, J.-H.; Chen, Q.-X. Inhibitory effects of fatty acids on the activity of mushroom tyrosinase. Appl. Biochem Biotechnol. 2010, 162, 1564-1573. [CrossRef]

21. Taherkhani, M. Chemical constituents, total phenolic content, antimicrobial, antioxidant and radical scavenging properties, chelating ability, tyrosinase inhibition and in vitro cytotoxic effects of Artemisia aucheri herbs. Pharm. Chem. J. 2017, 50, 736-745. [CrossRef]

22. Youssef, F.S.; Ashour, M.L.; Ebada, S.S.; Sobeh, M.; El-Beshbishy, H.A.; Singab, A.N.; Wink, M. Antihyperglycaemic activity of the methanol extract from leaves of Eremophila maculata (Scrophulariaceae) in streptozotocin-induced diabetic rats. J. Pharm. Pharmacol. 2017, 69, 733-742. [CrossRef] [PubMed]

23. Thabet, A.A.; Youssef, F.S.; El-Shazly, M.; El-Beshbishy, H.A.; Singab, A.N.B. Validation of the antihyperglycaemic and hepatoprotective activity of the flavonoid rich fraction of Brachychiton rupestris using in vivo experimental models and molecular modelling. Food Chem. Toxicol. 2018, 114, 302-310. [CrossRef] [PubMed]

24. Jelenkovic, L.; Jovanovic, V.S.; Palic, I.; Mitic, V.; Radulovic, M. In vitro screening of $\alpha$-amylase inhibition by selected terpenes from essential oils. Trop. J. Pharm. Res. 2014, 13, 1421-1428. [CrossRef]

25. Heydari-Majd, M.; Rezaeinia, H.; Shadan, M.R.; Ghorani, B.; Tucker, N. Enrichment of zein nanofibre assemblies for therapeutic delivery of Barije (Ferula gummosa Boiss) essential oil. J. Drug Deliv. Sci. Technol. 2019, 54, 101290. [CrossRef]

26. Mamadalieva, N.Z.; Youssef, F.S.; Ashour, M.L.; Akramov, D.K.; Sasmakov, S.A.; Ramazonov, N.S.; Azimova, S.S. A comparative study on chemical composition and antimicrobial activity of essential oils from three Phlomis species from Uzbekistan. Nat. Prod. Res. 2019, 1-6. [CrossRef]

27. Youssef, F.S.; Hamoud, R.; Ashour, M.L.; Singab, A.N.; Wink, M. Volatile oils from the aerial parts of Eremophila maculata and their antimicrobial activity. Chem. Biodivers. 2014, 11, 831-841. [CrossRef]

28. Thabet, A.A.; Youssef, F.S.; El-Shazly, M.; Singab, A.N.B. GC-MS and GC-FID analyses of the volatile constituents of Brachychiton rupestris and Brachychiton discolor, their biological activities and their differentiation using multivariate data analysis. Nat. Prod. Res. 2020, 34, 590-594. [CrossRef]

29. Labib, R.; Youssef, F.; Ashour, M.; Abdel-Daim, M.; Ross, S. Chemical composition of Pinus roxburghii bark volatile oil and validation of its anti-inflammatory activity using molecular modelling and bleomycin-induced inflammation in albino mice. Molecules 2017, 22, 1384. [CrossRef]

30. Mamadalieva, N.Z.; Youssef, F.S.; Ashour, M.L.; Sasmakov, S.A.; Tiezzi, A.; Azimova, S.S. Chemical composition, antimicrobial and antioxidant activities of the essential oils of three Uzbek Lamiaceae species. Nat. Prod. Res. 2019, 33, 2394-2397. [CrossRef]

31. Ayoub, I.M.; Youssef, F.S.; El-Shazly, M.; Ashour, M.L.; Singab, A.N.B.; Wink, M. Volatile constituents of Dietes bicolor (Iridaceae) and their antimicrobial activity. Z. Naturforsch. C 2015, 70, 217-225. [CrossRef] [PubMed]

32. Aboulwafa, M.M.; Youssef, F.S.; Gad, H.A.; Sarker, S.D.; Nahar, L.; Al-Azizi, M.M.; Ashour, M.L. Authentication and discrimination of green tea samples using UV-vis, FTIR and HPLC techniques coupled with chemometrics analysis. J. Pharm. Biomed. Anal. 2019, 164, 653-658. [CrossRef] [PubMed]

33. Mamadalieva, N.Z.; Böhmdorfer, S.; Zengin, G.; Bacher, M.; Potthast, A.; Akramov, D.K.; Janibekov, A.; Rosenau, T. Phytochemical and biological activities of Silene viridiflora extractives. Development and validation of a HPTLC method for quantification of 20-hydroxyecdysone. Ind. Crop. Prod. 2019, 129, 542-548. [CrossRef]

(C) 2020 by the authors. Licensee MDPI, Basel, Switzerland. This article is an open access article distributed under the terms and conditions of the Creative Commons Attribution (CC BY) license (http://creativecommons.org/licenses/by/4.0/). 